\title{
LA REGULACIÓN ADUANERA EN LA UNIÓN ADUANERA: LOS NIVELES SUPRANACIONALES Y NACIONALES
}

\author{
Customs regulation in the Customs Union: supranational and national levels
}

\author{
Victor Nikiforovich SIDOROV \\ Elena Victorovna SIDOROVA²
}

\begin{abstract}
Sumario:
I. Introducción. II. La noción de la regulación aduanera de la Unión Aduanera. III. La noción de la legislación de la Unión Aduanera. IV. El territorio único de la Unión Aduanera. V. Las ventajas y las desventajas del establecimiento del territorio único de la Unión Aduanera. VI. Código Aduanero de la Unión Aduanera. VII. Tratados internacionales de los estados miembros de la Unión Aduanera. VIII. Las Decisiones de la Comisión Eurasiática económica. IX. Las normas "soft law" como la fuente los derechos de la Unión Aduanera. X. Actas del Foro de Cooperación Económica Asia-Pacífico. XI. Conclusiones. XII. Fuentes.
\end{abstract}

Resumen: En éste artículo son examinados los cambios básicos que han pasado en el mecanismo normativo-jurídico de las relaciones aduaneras después de la formación de la Unión Aduanera. Además analiza la estructura de la legislación "Unión" aduanera y son reveladas las intercomunicaciones de sus elemento, es estableciendo la interacción entre niveles supranacional y nacional de la regulación normativa-jurídica de las relaciones aduaneras, también el artículo está dedicado a las cuestión para aclaración del lugar y el significado de las normas "soft law" entre otras fuentes del derecho aduanero de la Unión Aduanera.

Palabras clave: Regulación aduanera, Unión Aduanera, legislación aduanera, fuente del derecho, normas "soft law" del derecho

Abstract: The article analyses the main changes which have happened in the legal mechanism of the customs relations after formation of the Customs Union. The author considers the structure of "Union" customs legislation, identifies interrelations of its elements. Interaction between supranational and national levels of legal regulation of the customs relations is established. The article is devoted to the issues of clarifying the place and importance of the norms of «soft law» among other sources of customs law the Customs Union.

1 Doctor en Derecho y Doctor en Filosofía por la Universidad Estatal de Moscú M.V. Lomonosov y de la Universidad financiera al Gobierno de la Federación de Rusia, con especialidad en Derecho aduanero. Profesor de la Universidad financiera al Gobierno de la Federación de Rusia. Juez del Arbitraje a fondo "Oficina Jurídica” para el permiso de las disputas civiles. Jefe del Departamento de la regulación jurídica del comercio exterior y las aduanas de la Universidad Nueva de Rusia. Autor de las obras El derecho como el fenómeno de la cultura, Rusia, 1990; Derecho internacional privado, Rusia, 1998; Capacidad jurídica de las organizaciones sin ánimo de lucro, Rusia, 2007; El arbitraje internacional comercial, Rusia, 2010; Derecho aduanero, Iurait, Rusia, $5^{\text {a }}$ ed. 2014; Derecho aduanero: practicas, Iurait, Rusia, 2014.

2 Doctorante en Derecho por el Instituto Científico de Tribunal de Cuenta de la Federación Rusia. Consejera en el Departamento de Derecho Constitucional en el Ministerio de Justica de la Federación Rusia (2001 2012).Consejera de justicia de tercer nivel. 
Keywords: Customs regulation, Customs Union, customs legislation, source of law, "soft" law

\section{Abreviaturas:}

Foro de Cooperación Económica Asia-Pacífico (APEC)

Organización de las Naciones Unidas (ONU)

Organización Mundial del Comercio (OMC)

Negocios pequeños y medianos (PYME)

\section{INTRODUCCIÓN}

La legislación aduanera ocupa el lugar especial en el sistema jurídico de Rusia. En primer lugar, es una de las ramas más voluminosas de la legislación por la cantidad de las actas normativas jurídicas, que entran en ella. En segundo lugar, es la rama más internacionalizada de la legislación rusa que se desarrolla en la conformidad rigurosa con los estándares internacionales-jurídicos de la regulación aduanera, que determinan en parte considerable nacional el modelo de la regulación aduanera. En tercero, la regulación aduanera y la legislación aduanera abastecen el ingreso más de mitad de todos los ingresos lucrativos en el presupuesto federal de Rusia.

Los cambios que pasan en el derecho aduanero de Rusia a declarar testimonian sobre las transformaciones en el mecanismo de la regulación jurídica de las relaciones aduaneras.

En vez del mecanismo nacional de la regulación aduanera ha llegado el mecanismo compuesto, que contempla dos niveles de la regulación: supranacional (la legislación aduanera de la unión Aduanera) y la legislación nacional. Además uno de los esenciales principios del derecho aduanero se hizo un principio como prioridad de la regulación supranacional.

\section{LA NOCIÓN DE LA REGULACIÓN ADUANERA DE LA UNIÓN ADUANERA}

Con la creación de la Unión Aduanera incluye tres miembros: Bielorrusia, Kazajistán y Federación Rusa. Por lo que se acepta el Código Aduanero de la Unión Aduanera, formando el sistema compuesto legislativo de la regulación aduanera que incluye dos niveles: la legislación aduanera de la Unión Aduanera y la legislación nacional.

La noción de la regulación aduanera de la Unión Aduanera implica la distribución de algunos aspectos de las aduanas entre el nivel supranacional (el nivel de la Unión Aduanera) y nacional (el nivel de la regulación aduanera del estado miembro de la Unión Aduanera).

El rasgo del modelo «eurasiático» de la Unión Aduanera es lo que los estados participantes han retenido una serie de los poderes esenciales por la regulación aduanera. Los poderes nacionales por la regulación aduanera se realizan en concordancia con las actas legislativas aceptadas en cada estado miembro de la Unión Aduanera, que componen el segundo nivel del mecanismo de la regulación en la Unión Aduanera

Las leyes de los estados de los miembros de la Unión Aduanera no pueden independientemente realizar la regulación aduanera. Ellos las derivadas de la legislación de la Unión Aduanera no pueden contradecirlo. Además aquellas preguntas de la regulación aduanera, 
que son el objeto de las leyes nacionales, son delegadas a los poderes legislativos de los estados de los miembros por el código directamente aduanero de la Unión Aduanera.

Así el mecanismo jurídico de la regulación de las relaciones aduaneras, que se ha formado después de la creación de la Unión Aduanera, se distingue ante legislaciones aduaneras que existía de la Federación Rusa.

La diferencia del principio es que el mecanismo de la regulación jurídica de las relaciones aduaneras incluye los dos subsistemas de interacción y subordinación - legislación aduanera de la Unión Aduanera y las legislaciones nacionales de las aduanas de los estados miembros.

La legislación aduanera de la Unión Aduanera posee con relación de la legislación nacional aduanas eficacia jurídica y difunde su acción en toda la zona de la Unión Aduanera.

Conforme al principio de la prioridad de la regulación supranacional, la regulación nacional en el marco de la Unión Aduanera es posible solamente hasta cuando no tomen las disposiciones correspondientes en el nivel supranacional.

Era confirmada una pretensión a abarcar la regulación a nivel de la Unión Aduanera de las esferas básicas de las aduanas. La ley nacional de la regulación aduanera del estado del miembro de la Unión Aduanera debe corresponder a la legislación aduanera de la Unión Aduanera, y su acción difundir solamente en el territorio del estado dado.

\section{LA NOCION DE LA LEGISLACIÓN DE LA UNIÓN ADUANERA}

La legislación de la Unión Aduanera está determinada en el Código Aduanero a través del establecimiento de su objeto, estructura, también los límites espaciales de la acción.

La legislación aduanera de la Unión Aduanera representa un cuerpo de reglas para todos los estados miembros de la Unión Aduanera. Su objetivo consiste en la reglamentación jurídica de las relaciones aduaneras, que surgen en la Unión Aduana.

El derecho aduanero tiene su objeto de la regulación, ya que en su composición entran las relaciones grupos de sociales distintos, que se distinguen por el carácter específico (las relaciones sobre la organización de las aduanas en la Federación Rusa y en la Unión Aduanera, con despacho aduanal, control aduanero, infracción en la esfera aduanera y la responsabilidad por acciones; las relaciones que aplican los procedimientos aduaneros, la participación de Rusia en la cooperación internacional-jurídica en la esfera aduanera; las relaciones en el esfera de tarifas, los impuestos; las relaciones en la esfera de la estadística aduanera y nomenclatura económico externo de la Unión Aduanera).

El rasgo característico para todas estos relaciones son las que se forman durante la realización aduanera vinculado de todas maneras con la circulación de mercancía a través de la frontera de la Unión Aduanera.

Además la circulación de mercancías puede realizarse en la importación de las mercancías y los medios de transporte al territorio de la Unión Aduanera, también a su exportación del territorio aduanero. Por esto, el derecho aduanero tiene su ámbito de la regulación - 
mercancías y medios de transporte en el circulado a través de la frontera aduanera de la Unión Aduanera.

El código aduanero, fuente básica jurídica de la regulación aduanera en marco de la Unión Aduanera, alrededor de que ejerce una formación «de la legislación Unión aduanera».

En el sistema de la legislación aduanera, el acto que posee eficacia jurídica, es el código Aduanero.

Las fuentes de la legislación de la Unión Aduanera pueden estar en las consecuencias siguientes: Código Aduanero de la Unión Aduanera; tratados internacionales de los estados miembros de la Unión Aduanera; decisiones de la Eurasiática económica comisión; Códigos aduaneros de los estados-participantes de la Unión Aduanera; decisiones de los gobiernos de los estados-participantes de la Unión Aduanera; regulaciones legislativas de los servicios aduaneros de los estados-participantes de la Unión Aduanera.

Así, el marco de la Unión Aduanera funciona en sistema de la legislación con seis niveles. Al nivel supranacional: Código Aduanero de la Unión Aduanera, tratados internacionales de los estados miembros de la Unión Aduanera y decisión de la Comisión de la Unión Aduanera, y nivel nacional - los Códigos aduaneros de los estados-participantes de la Unión Aduanera, la decisión de sus gobiernos y las regulaciones legislativas de sus servicios aduaneros.

La legislación de la Unión Aduanera funciona en todo el territorio, a diferencia de nacional legislación sobre la regulación aduanera, que se aplica solamente en el territorio del estado, que lo ha aceptado.

\section{EL TERRITORIO ÚNICO DE LA UNIÓN ADUANERA ${ }^{3}$}

El derecho aduanero difunde su acción en el territorio único de la Unión Aduanera conforme del art. 2 del Código Aduanero entran los territorios de la República Bielorrusia, República Kazajistán y Rusia, también que se encuentran afuera de los límites de los territorios de los estados miembros de la Unión Aduanera de las islas artificiales, el ajuste, las construcciones y otros, en relación cuales del estado miembros de la Unión Aduanera poseen la jurisdicción exclusiva.

La jurisdicción exclusiva se establece incluso respecto a aduanero, fiscal, sanitario y de inmigración de las leyes y las reglas, también las leyes y las reglas que tocan la seguridad.

Afuera de los límites del mar territorial de la Federación Rusa se encuentra la Zona económica exclusiva. Pero ella no es parte del territorio nacional de la Federación Rusa, pero en ella se distribuye la jurisdicción exclusiva de Rusia. Por ejemplo, a veces en la práctica surge la pregunta sobre la posibilidad de la carga fiscal de impuesto sobre el valor agregado de la realización de las mercancías en la zona económica exclusiva.

Juzgando lógicamente, se puede llegar a la conclusión errónea de que la recaudación de la carga fiscal de impuesto sobre el valor agregado de la realización de las mercancías en la zona económica exclusiva no es admisible porque la Zona económica exclusiva no entra en el territorio de la Federación Rusa.

La opinión expresada anteriormente confirma en parte que se encuentra en la carta de el Servicio fiscal y el Ministerio de Finanzas de Rusia del 25 de diciembre de 1996 № VZ-603/887 y № 04-03-08 «Impuesto sobre el valor agregado», donde es indicado: «... el mar que

3 El uso en la nueva legislación de los términos «el territorio único de la Unión Aduanera» y «la frontera de la Unión Aduanera» un cambio de las nociones «el territorio de la Federación Rusa» $\mathrm{y}$ «la frontera de la Federación Rusa» es la innovación. 
se encuentra afuera de los límites de las aguas jurisdiccionales de la Federación Rusa (afuera de los límites de la zona a 12 mil millas), es el territorio del océano mundial, pero no se refiere al territorio de la Federación Rusia.

Por esto, la producción del mar, obtenida en el océano mundial y realizado directamente en las regiones de la producción marina sin intersección de la frontera aduanera de la Federación Rusa; el impuesto sobre el valor agregado no tiene carga fiscal como la producción, lo obtenido y lo realizado afuera de los límites del territorio de la Federación Rusa».

El régimen jurídico de la Zona económica exclusiva es semejante en muchos aspectos al régimen jurídico en el territorio del océano Mundial y la realización de la producción en el territorio del océano Mundial no crea el objeto de la imposición del impuesto sobre el valor agregado.

Pero en la carta del Servicio fiscal y el Ministerio de Finanzas de Rusia han planteado la condición subsidiaria: «sin la intersección de la frontera aduanera de Rusia».

En relación a esto, la respuesta correcta es la siguiente: la importación de las mercancías del territorio de la Unión Aduanera en la Federación Rusa en Zona económica exclusiva no está reconocido el objeto de la imposición del impuesto sobre el valor agregado, pero la importación de las mercancías del territorio del estado extranjero debe reconocerse en la Zona económica exclusiva por el objeto de la imposición del impuesto sobre el valor agregado. La noción de la frontera de la Unión aduanera contiene en el 2do artículo de Código Aduanero: los límites del territorio son la frontera de la Unión Aduanera.

\section{LAS VENTAJAS Y LAS DESVENTAJAS DEL ESTABLECIMIENTO DEL TERRITORIO ÚNICO DE LA UNIÓN ADUANERA}

Las ventajas del establecimiento del territorio único de la Unión Aduanera se reducen a lo siguiente:

Gracias a la formación del territorio Único de la Unión Aduanera hay un proceso de formación en el mercado de las mercancías comunes, mano de obra y capitales de tres países con el territorio enorme y la población cerca de 170 millones de personas.

La asociación de la Federación Rusa, República Bielorrusia y República Kazajistán en los límites Comisión Eurasiática Económica permite eliminar las barreras aduaneras dentro de él. Así, a mediados del 2010, el control aduanero de las mercancías era llevado por completo a la frontera exterior de la República Bielorrusia, y desde el verano 2011 la frontera exterior de la Unión Aduanera se hacía también en la frontera exterior de la República de Kazajistán.

Si antes la mercancía que se dirigía de la República Bielorrusia a la República Kazajistán, atravesaba dos fronteras aduaneras (Rusia y de Kazajstán) y la mitad del tiempo se iba por formalización, los impuestos alcanzaban $15 \%$ del precio del costo de la mercancía, pero todo ha cambiado; las formalizaciones de los declaraciones de exportación no son necesarias; las mercancías de propia producción se excentan de derechos aduaneros, así como el extranjero, producido para el consumo interior por uno de los países participantes de la Unión Aduane- 
ra; no se aplican las medidas de la regulación sin tarifas (no es necesario tener las licencias, el permiso y paga las cuotas).

Además, consiguió formar el acceso único a cualquier mercancía extranjera. De dónde provenían, en qué país de la Unión Aduanera era introducido y dónde atravesaba la frontera común aduanera.

Así, el levantamiento de las barreras dentro de la Unión Aduanera ha influido de la manera más favorable posible sobre la circulación de mercancías de todos los participantes; el volumen del comercio mutuo, según los especialistas ha crecido un 25 a $30 \%$.

Ha pasado la necesidad de llevar los gastos adicionales para los servicios de los intermediarios aduaneros.

Consiguió formar sobre el espacio postsoviético el órgano supranacional de la dirección de Comisión de la Unión Aduanera.

Así los primeros resultados de la apertura del mercado mundial, el mercado de la venta de la producción rusa es extendido, volumen del comercio en la Unión Aduanera se ha aumentado, se forma el ambiente general competitivo y generan nuevos puestos de trabajo.

Las desventajas del establecimiento de la Unión Aduanera son las siguientes:

El consumidor «no ha ganado» de las apariciones de la Unión Aduanera, ya que los precios de las mercancías de consumo no han bajado.

Ha pasado «la inundación» del mercado interior de la Federación Rusa y la República Bielorrusia por las mercancías baratas chinas. Debido a que la industria ligera a través de la República Kazajistán empezaba el tránsito a pararse en los estados miembros de la Unión Aduanera.

En los límites de la Unión Aduanera no se consiguió pasar por la declaración electrónica;

No consiguió la unificación en la decisión de la serie de preguntas en la esfera de la regulación cambiaria. Por ejemplo, si la persona jurídica rusa compra la moneda nacional de la República de Kazajistán para los pagamentos aduaneros cayera bajo el control de la regulación cambiaria de Rusia.

Es necesaria la observación de la exigencia sobre la apertura del pasaporte, las transacciones, si la compañía rusa va a realizar la entrega de la producción a la República Kazajistán.

\section{CÓDIGO ADUANERO DE LA UNIÓN ADUANERA}

Para el mantenimiento de la regulación aduanera en la zona de la Unión Aduanera de Rusia, Bielorrusia y Kazajistán fue elaborado Código Aduanero de la Unión Aduanera. Para la República Kazajistán y la Federación Rusa Código Aduanero de la Unión Aduanera ha entrado en vigor en el 1 de julio de 2010, y para la República Bielorrusia en el 6 de julio de 2010.

El Código de la Unión Aduanera ocupó el lugar clave en la regulación del comercio exterior se hizo el acta básica legislativa de la regulación en la Unión Aduanera.

En el sistema de la legislación del Código Aduanero tiene lugar central: sus posiciones tienen prioridad, vigor superior sobre todas otras normas de la legislación de la Unión Aduanera, actas del órgano supranacional que funciona en toda la zona de la Unión Aduanera.

El principio de la conformidad de todas las fuentes del derecho aduanero a las prescripciones del Código Aduanero representa la garantía jurídica de la unidad del sistema de la regulación en la Unión Aduanera.

La estructura del Código Aduanero refleja las direcciones básicas de la regulación aduanera e incluye las secciones dedicadas: las situaciones generales en la Unión Aduanera, im- 
puestos, control aduanero, operaciones aduaneras, los procedimientos aduaneros y los rasgos de la circulación de la mercancía a través de la frontera de la Unión Aduanera

\section{TRATADOS INTERNACIONALES DE LOS ESTADOS MIEMBROS DE LA UNIÓN ADUANERA}

Tratados internacionales de los estados miembros de la Unión Aduanera conforme segundo nivel de la legislación de la Unión Aduanera y correspondiente ceden por el vigor al Código de la Unión Aduanera.

Tratados internacionales que componen la base jurídica de la Unión Aduanera se puede subdividir en dos grandes grupos, según el tiempo de su aceptación y la tendencia de la destinación especial:

1) Dictadas antes de la formación de la Unión Aduanera (los tratados internacionales actúan en Comunidad Económica Eurasiática. Por ejemplo, el Tratado constitutivo de la Comunidad Económica Eurasiática del 10 de octubre de 2000.

2) Dictadas después de la formación de la Unión Aduanera (los tratados internacionales dirigidos para conclusión formación de la estructura jurídica de la Unión Aduanera). Por ejemplo, el Tratado sobre la Comisión Eurasiática económica del 18 de noviembre de 2011.

Los dos primeros niveles de las fuentes de la legislación aduanera (el Código de la Unión Aduanera y los tratados internacionales de los estados miembros), que componen la base jurídica de la dirección estratégica en la Unión Aduanera, regulan las relaciones más importantes y básicas.

Es evidente que las decisiones aceptadas por las preguntas estratégicas importantes, deben tomar en la forma de los tratados internacionales aceptados por el principio de la soberanía, que poseen los estados miembros de la Unión Aduanera.

Debemos distinguir las nociones de los tratados internacionales de los estados miembros de la Unión Aduanera y los tratados internacionales del estado miembro de la Unión Aduanera, que regulan las relaciones aduaneras.

En el primer caso se trata de los tratados que fueron aceptados por la Unión Aduanera, por todos los estados y sus miembros.

Tales tratados internacionales pueden ser solamente multilaterales, y esos son las actas de la legislación de la Unión Aduanera.

En el segundo se trata sobre tratados internacionales multilaterales y bilaterales, que pueden ser aceptados por una de las partes es el estado miembro de la Unión Aduanera.

Por su contenido tales tratados internacionales no son aceptados por la relación de la Unión Aduanera y no entran en el sistema de la legislación de la Unión Aduanera, pero pueden ser la fuente del derecho nacional aduanero y regular las relaciones aduaneras conforme a los estados miembros de la Unión Aduanera. Por ejemplo: el Convenio de colaboración y ayudo mutua administrativa en los asuntos aduaneros entre el Gobierno de la Federación Rusia y el Gobierno de la República Vietnam Socialista.

Un ejemplo interesante son los tratados internacionales de la Federación Rusia, que regula las relaciones aduaneras, pero no están en el acta de la legislación de la Unión Aduanera, solamente se representa en la Convención Internacional de la simplificación y la armoni- 
zación de los procedimientos aduaneros una de las fuentes básicas del derecho moderno internacional aduanero.

Actualmente los tres estados son miembros de la Unión Aduanera son los participantes de esta Convención, pero la Convención no está dentro del acta de la legislación de la Unión Aduanera, actuando como fuente del derecho aduanero para cada uno los estados participantes de la Unión Aduanera.

\section{LAS DECISIONES DE LA COMISIÓN EURASIÁTICA ECONÓMICA}

El tercero nivel de la legislación aduanera conforme a las decisiones del órgano supranacional de la Unión Aduanera de la realización de la dirección operativa por los procesos de la integración económica surge la necesidad de la formación de los institutos supranacionales.

La necesidad de la regulación supranacional es sensible especialmente en la esfera aduanera: las fluctuaciones frecuentes de la coyuntura mercantil y los mercados cambiarios condicionan la necesidad de la formación de los mecanismos de la aceptación de las decisiones de administración, las cuales pueden rápidamente, sin maniobras procedimentales corregir la política de comercio exterior.

En 2012 constantemente el órgano único activo que regula la Unión Aduanera y el Espacio Económico Común tienen la Comisión Eurasiática económica; el problema principal es el mantenimiento de las condiciones del funcionamiento y el desarrollo de la Unión Aduanera y el Espacio Económico Común, también la fabricación de las proposiciones en la esfera de la integración económica.

La Comisión Eurasiática económica junto con la política aduanera y la regulación de comercio exterior (regulación de tarifas, administración aduanera, abono y distribución de los derechos de importación, establecimiento de los regímenes comerciales respecto a los terceros, estadística del comercio exterior y mutuo) realizan también la regulación supranacional en la esfera de la política macroeconómica, monetaria, competitiva, energética, monopolio, transportaciones, migración laboral, mercados financieros, compras del estado y municipales.

En el límite de sus competencias la Comisión acepta las decisiones que tiene el carácter obligatorio para los estados que son miembros de la Unión Aduanera y las recomendaciones que no tienen dicho carácter.

Las decisiones de la Comisión son la parte de la legislación aduanera y se aplican en todo el territorio de la Unión Aduanera: las Decisiones de la Comisión entran en la base contratojurídica de la Unión Aduanera y el Espacio Económico Común, las cuales están sujetas a la aplicación directa en los territorios de las Partes.

Entre las actas aceptadas por el Consejo de la Comisión Eurasiática Económica: Decisión del 16 de julio de 2012, № 54 "Sobre la afirmación de la nomenclatura única mercantil del comercio exterior y la tarifa única de la Unión Aduanera". Decisión del 16 de julio de 2012, № 55 "Sobre la aplicación por la República Bielorrusia y la República Kazajistán de los tipos impositivos, diferentes de tipos de la tarifa única de la Unión Aduanera respecto a las categorías separadas de las mercancías".

Entre los primeros actos del Colegio de la Comisión Eurasiática Económica está la Decisión del 7 de marzo de 2012, № 1 "Sobre algunas cuestiones de la aplicación de las medidas especiales protectoras, antidumping y de compensación en el territorio único aduanero del 
la Unión Aduanera". Decisión del 12 de diciembre de 2012, № 273 "Sobre la aplicación del método de la adición (el método 5) a la definición del coste aduanero de las mercancías".

Las actas del órgano supranacional funcionan en todo el territorio de la Unión Aduanera y a ellos se aplican las reglas generales de la acción de la norma del derecho aduanero según el tiempo. Los casos especiales de la aplicación de las normas de la legislación aduanera pueden aplicarse en los casos previstos por el Código Aduanero o los tratos internacionales de los estados miembros de la Unión Aduanera.

La legislación nacional de las aduanas es derivada del derecho de la «Unión» aduanera y se forma en cada estado miembro de la Unión en concordancia con el Código y otras actas de la legislación de la Unión Aduanera alrededor del acta nacional legislativa, que en la Federación Rusa es la Ley federal del 27 de noviembre de 2010, № 311-LF “Sobre la regulación aduanera en la Federación Rusa”. En la República Bielorrusia, el Código Aduanero del 4 de enero de 2007, № 204-L. En la República Kazajistán el Código del 30 de junio de 2010, № 296-IV "Sobre las aduanas en la República Kazajistán".

Los límites espaciales de la acción de la legislación nacional de los estados miembros de la Unión Aduanera sobre la regulación estarán determinados en las leyes correspondientes.

Por ejemplo, en el art. 7 de la Ley federal Sobre la regulación aduanera, la acción de las actas de la legislación de la Federación Rusa sobre las aduanas en el espacio está determinada del siguiente modo: las actas de la legislación sobre las aduanas, otras actas jurídicas en la esfera de las aduanas que funcionan en todo el territorio, también en los territorios que se encuentran en la zona excepcional económica y sobre la plataforma continental de la Federación Rusa de las islas artificiales, los ajustes, las construcciones que la Federación Rusa realiza acorde a la jurisdicción en concordancia con la legislación y las normas del derecho internacional.

También por los tratados internacionales que componen la base tratados-jurídicos de la Unión Aduanera, puede ser prevista la aplicación de las actas de la legislación de la Federación Rusa sobre las aduanas en el territorio del estado miembro de la Unión Aduanera a la exportación de las mercancías, proveniente del país de origen, es la Federación Rusa o de los productos de su elaboración del territorio de este estado miembro de la Unión Aduanera por los límites del territorio único.

En el nivel nacional de la regulación con las relaciones aduaneras pueden aplicarse como las actas internas de la legislación de las aduanas, así como tratados internacionales con la participación del estado miembro de la Unión Aduanera, las cuales no son las actas de la legislación de la Unión Aduanera.

Tales casos surgen en la práctica de la aplicación, cuando la norma del acta interna legislativa entra en la contradicción con la norma del tratado internacional.

Por ejemplo, en el art. 3 ero. del Código de la República Kazajistán Sobre las aduanas en la República Kazajistán: la legislación Aduanera de la República Kazajistán se funda en la Constitución de dicha República y consiste en: 1) el Código; 2) las actas normativas jurídicas que aceptan es prevista por el Código presente. Si por el tratado internacional que está ratificado por la República Kazajistán son establecidas otras reglas, las que contienen en el Código, se aplican las reglas del tratado internacional. 


\section{LAS NORMAS “SOFT LAW" COMO LA FUENTE LOS DERECHOS DE LA UNIÓN ADUANERA}

El círculo de las fuentes del derecho de la Unión Aduanera es muy extenso y diverso.

Por la relación uno a otro se sitúa en el orden rigurosamente jerárquico, sometiendo, detalladamente y completando uno a otro.

Parece que a las fuentes del derecho aduanero debemos llevar las normas "soft law", que tienen el carácter de recomendación y se distinguen por la alta flexibilidad.

Por ejemplo de la norma del derecho "soft law" es la Declaración de Arusha sobre la ética profesional (llamado también Declaración de Arusha de la honestidad en la aduana), aceptado en 1993 y revisado en 2003. Este documento tiene el carácter no obligatorio y representa una serie posiciones básicas dirigidas a la lucha contra la corrupción a la esfera aduanera.

Para la prevención del fenómeno negativo y el aumento del nivel de la honestidad en los órganos aduaneras es invitado a seguir los estándares siguientes de las actividades: regulación mínima administrativa, transparencia de las acciones, las decisiones aceptadas, automatización de las aduanas, división estratégica, rotativa y traslado del personal, responsabilidad personal, subordinación, procedimientos especiales por enlace del personal, alto espíritu moral, cultura de organización, desarrollo de la auditoría e investigaciones dentro del sistema interno, aceptación del Código especial de la conducta, enseñanza profesional permanente, recompensa adecuada para el trabajo, formación de las relaciones especiales con los corredores y los representantes de una rama de la industria.

En el 2003, la Declaración de Arusha fue renovada en el curso 101/102 de las Sesiones del Consejo de la cooperación aduanera. Debemos notar que en concordancia con Declaración de Arusha la responsabilidad básica por la prevención de la corrupción debe estar sobre el jefe y ejecutivo de la dirección de la administración Aduanera. En la Declaración es subrayada especialmente la necesidad de la lucha contra la corrupción en un alto nivel estatal, se nota también que la lucha contra la corrupción no debe llevar el carácter de corta duración y esporádico, debe ser de sistema y larga duración.

Las normas del derecho "soft law" debe también llevar la Declaración de la Organización de las Naciones Unidas contra la corrupción y los sobornos en las transacciones comerciales e internacionales, 58/4, aceptadó por la resolución de Asamblea General del 31 de octubre de 2003.

La corrupción es uno de los problemas actuales en la actual Rusia. La mayoría de los rusos son obligados a dar sobornos a los órganos que comprueban o que registran. Además muchos documentos normativos jurídicos aceptados por el Gobierno de la Federación Rusa y los órganos de autogobierno local contribuyen al desarrollo de la corrupción. A pesar de todas las declaraciones de los funcionarios superiores, los órganos de los asuntos interiores, los órganos aduaneros la eficiencia de la lucha contra la corrupción en la Federación Rusa se queda en el nivel muy bajo. En esta relación las normas el derecho "soft law" merecen la investigación fija. 


\section{ACTAS DEL FORO DE COOPERACIÓN ECONÓMICA ASIA-PACIFICO (APEC) ${ }^{4}$}

Durante el examen superficial los actos de APEC puede haber una opinión, que las actas se refieren al nivel supranacional del sistema de la legislación de la Unión Aduanera. Pero este punto de vista no resiste crítica.

Primeramente, el foro internacional de APEC creado en noviembre de 1989 en la $1 \mathrm{r}^{\mathrm{a}}$ Conferencia de los Ministros de Exteriores y la economía de 12 países de cuenca del Pacifico en Canberra (Australia). APEC no tiene el estatuto, por eso él no puede considerarse como organización internacional.

En segundo lugar, la forma básica de la actividad de organización del foro de 1993 son las cumbres anuales (los encuentros no oficiales) de los líderes de los países APEC, se ponen en curso las declaraciones que conducen el total general de la actividad del foro en el año pasado y que determinan las perspectivas de su actividad ulterior.

Los documentos indicados no están sujetos al registro ulterior en la Secretaria de la Organización de las Naciones Unidas (ONU). Por fuerza de la causa indicada no adquieren el estatus del tratado internacional, son las actas que no imponen a los estados de las obligaciones jurídicas y no pueden ser realizados por la vía forzada, digamos, a diferencia de las decisiones del Consejo de Seguridad de Naciones Unidas y la Asamblea General de la ONU.

En tercer lugar, es posible decir que para APEC es característica la semi ausencia total del aparato especial administrativo. Siendo formado como el foro libre consultivo sin estructura rígida o un gran mecanismo burocrático, APEC incluye solamente a los 23 diplomáticos que presentan a los países miembros del APEC, también 20 empleados locales obreros (trabajadores asalariados). Por todo lo anteriormente mencionado esto habla, aunque en los límites APEC pasan bastante a menudo los encuentros de los Ministros de exteriores y el comercio exterior de los países participantes, pero en el foro falta capacidad jurídica.

Todavía a APEC le faltan los poderes vinculados a la coacción de los estados miembros para la realización de las obligaciones contractuales aceptadas. Al comparar con la Organización Mundial del Comercio (OMC), tal organización es competente para realizar las medidas de la coacción al permiso de los conflictos entre los estados miembros de la OMC.

Como se ha dicho, las actas APEC no deben pertenecer al nivel supranacional del sistema de la legislación de la Unión Aduanera. Con todo eso, la variedad examinada de los documentos que acepta la participación activa de la Federación Rusa, pueden ser llevadas a las fuentes del derecho de la Unión Aduanera. Las actas APEC son las cuales «soft law», el derecho de la Unión Aduanera.

La separación ente el sector privado internacional y el público en el grupo especial de las normas «soft law» han servido, a su tiempo, como el motivo para la gestión a discusión, que no se calma y hasta ahora, se considera que al derecho internacional le es inherente la jerarquía especial de las normas: «rígidas» y «blandas». Las normas «rígidas» son reglas y las «blandas» son las recomendaciones. La ventaja de las normas «blandas» consisten en la

\footnotetext{
4 APEC es una organización internacional económica creada para el desarrollo de los enlaces de integración entre los países de los estados del Océano Pacífico. Originariamente APEC fue fundado en Canberra (Australia) y era constituido por 12 países. En la actualidad, la organización une las economías de 21 países del niveles diferentes del desarrollo (Australia, Brunei, Vietnam, Hong Kong, oficialmente Región Administrativa Especial de Hong Kong de la República Popular China, Canadá, La República Popular China, Indonesia, Malasia, México, Nueva Zelanda, Papúa Nueva Guinea, Perú, Rusia, Singapur, Estados Unidos, Tailandia, Taiwán, Chile, Filipinas, Corea del Sur y Japón).
} 
flexibilidad inherente. Pueden adaptarse a los rasgos de las relaciones jurídicas reguladas, así como a los sujetos que participan en estas relaciones.

Los documentos que acepta APEC por distintas características, tales como: tarifas comerciales; regulación sin tarifas del comercio mutuo; servicios internacionales; inversiones internacionales; estandarización de las mercancías y los servicios; procedimientos aduaneros; derechos de la propiedad intelectual; política competitiva; distribución de los mandatos del estado; las reglas que tocan el origen la mercancía; la intermediación en las disputas; la movilidad de los empresarios; la introducción de los resultados de la ronda uruguaya de las negociaciones por el comercio en los límites de la OMC; la recogida y el análisis de la información tienen el carácter no obligatorio, solamente de recomendación, estos normas del derecho «soft law», que son llamadas inmediatamente a regular las relaciones internacionales.

En relaciona la explicación anterior, la Decisión aceptada por la APEC, en 1995, "Sobre crear el Consejo de trabajo consultivo hace más eficaces los trabajos", a través de la interacción APEC con los países participantes.

Cada país miembro de la APEC fija en el Consejo de trabajo consultivo hasta tres representantes que expresan los intereses de los distintos círculos de los negocios nacionales. Anualmente el Consejo de trabajo consultivo presenta el informe con las recomendaciones generalizadas de los representantes competentes en el sector privado sobre la realización de los documentos del programa APEC.

Las recomendaciones son dirigidas, como regla para la resolución de los problemas más esenciales de la cuenca del Pacífico, por ejemplo: simplificación de los trámites de visado para los hombres de negocios de la economía APEC, la baja de las barreras en la vía de las mercancías y las inversiones.

Así, es posible hablar sobre la creación de los límites en APEC de las normas del derecho «soft law» dirigido a la formación del ambiente especial, en que los límites tienen un cambio intenso para la información entre los participantes APEC sobre la actividad internacional comercial. Gracias a la acción de las normas «soft law» se realiza la formación del espacio único e informativo de la cuenca del Pacífico.

Es importante notar que el Consejo de trabajo consultivo se hacía el iniciador de la creación del grupo del Consejo especial por los negocios pequeños y medianos (PYME). Las esferas de su actividad son: el trabajo sobre la ampliación del acceso de las PYME a los recursos financieros, información y tecnologías de comunicación; refuerzo de la interacción de las empresas pequeñas y medianas con los representantes de las estructuras estatales.

El grupo del Consejo de trabajo consultivo por las finanzas se ocupa de la introducción de los estándares financieros, tomados para la comunidad internacionales, el refuerzo del sistema financiero internacional.

Estudia el desarrollo de los mercados interiores del capital en la cuenca del Pacífico. El Grupo del Consejo de trabajo consultivo por las tecnologías trabaja sobre la estimulación del comercio electrónico, ocupando de la elaboración de las medidas de la reducción de la ruptura entre las economías APEC en el uso de las tecnologías digitales.

Es importante subrayar que, a pesar del carácter «suave» de la acción de los documentos creados por APEC, pero ellos juegan el papel visible en el campo de la armonización y la unificación de las normas jurídicas-internacionales que realizan el mantenimiento jurídico de la actividad del comercio transfronterizo.

Las normas APEC, siendo por el carácter las recomendaciones, al mismo tiempo representan una cierta forma de expresión coordinada de los puntos de vista económicos y las 
posiciones de los estados de la cuenca del Pacífico por las preguntas básicas del comercio mundial y de este punto de vista pueden ser examinados como la etapa esencial del proceso general en los límites del derecho internacional aduanero.

En esta relación las resoluciones y la declaración APEC no son las medidas simples las recomendaciones abstractas y los documentos político-jurídicos que expresan a la apreciación, intenciones y métodos de la decisión práctica de los problemas internacionales que están en el orden del día de los estados de la cuenca del Pacífico.

En concordancia con la tradición que se ha formado, el derecho está determinado en la mayoría de los casos como ordenamiento de las normas, es decir, en concordancia con el «criterio normativo». Por esto, resulta que la fuente del derecho puede actuar solamente en las actas jurídicas que tienen el carácter normativo. Así, los científicos soviéticos de Olimpiad Ioffe y Miguel Shargorodskiy contaban que «en calidad de la forma de la expresión del derecho actúa la norma jurídica» ${ }^{5}$. Samuel Zivs ha atado más rudamente «la fuente del derecho» a "la fuente de las normas del derecho". La tradición de la definición de las fuentes del derecho a través de las normas del derecho asiste y en la ciencia jurídica moderna. A tal acceso todas otras actas jurídicas, gracias a que se realiza la influencia sobre las relaciones jurídicas concretas, tienen el significado no normativo, y, por consiguiente, las fuentes del derecho no pueden ser.

A tal acceso todas otras actas jurídicas, gracias a que se realiza la influencia sobre las relaciones jurídicas concretas, tienen el significado no normativo, y de ahí, las fuentes del derecho no pueden ser normativas.

Al mismo tiempo entre tales actas internacionales jurídicas es posible distinguir el grupo, que aunque no establece las normas jurídicas, pero juega el papel importante que regula durante el empalme «estrecho» los regímenes económicos, las reglas de la regulación técnica que funcionan en la Unión Europea, en APEC y en marco de la Unión Económica Euroasiática, la elaboración de las reglas universales y claras «para el trabajo del negocio sobre el espacio del Euro-Atlántico, la Eurasiático y cuenca del Pacífico»7.

En el 2002, Rusia ha asistido al foro por la cooperación efectiva en la esfera de la empresa de innovación, la sesión del grupo APEC de trabajo por las telecomunicaciones y el simposio de inversiones, en que eran producidas las recomendaciones correspondientes. En noviembre del 2004 en la cumbre APEC en Santiago eran aprobados los principios que dirigen del control sobre el traslado a la región APEC de los misiles teledirigidos.

A principios del 2005 era apoyada la iniciativa rusa en APEC por el aumento de la eficiencia de energía de la economía. En la actualidad en la fase acabada se encuentra el examen del proyecto sobre la aplicación «de los mejores modelos» de la práctica acumulada por las economías APEC en el campo del comercio electrónico y las compras estatales.

Así, el significado práctico de las normas «soft law», creadas en marco APEC, consisten también en lo que sirven en algunos casos como el punto de partida para la elaboración de

\footnotetext{
5 IOFFE, Olimpiad, SHARGORODSKIY, Miguel, Las preguntas de la teoría del derecho, Rusia, 1961, p. 134.

${ }^{6}$ Ibidem, p. 10.

7 Vladivostok-2012: El aviso ruso para el foro APEC. (El Artículo del Presidente de Rusia Vladímir Putin, instalado en la edición asiática del periódico principal americano de trabajo «The Wall Street Journal»), // http://rus.apec2012.ru, 22 de abril de 2014.
} 
su base distinta de los acuerdos internacionales y las convenciones, también las normas de la legislación internacional.

Aparentemente sería más correcto examinar las fuentes del derecho aduanero en el sentido ancho y estrecho. En el sentido ancho, tales fuentes todas son las actas jurídicas, y en estrecho, solamente actas jurídicas que contienen las normas jurídicas.

Nina Granat es de la opinión sobre la polisemia de la noción «la fuente del derecho», por ello se separan en largo y estrecho los accesos a este término: «En largo, como las causas y la ley formaciones o la génesis del derecho; en corto, como el modo de la fijación y la existencia de la norma del derecho o como la fuente de que el jurista o cualquier otro sujeto del derecho saca las normas del derecho»8.

La noción, «la fuente del derecho» no tiene un significado que es condicionado por los factores distintos que influyen en la formación jurídica. Con esto no debe corregir, además, la posición de investigación, como esto ha inclinado el hecho de algunos autores durante el tránsito del nivel meta en una rama de la cienciag, en caso de que se trata de "las fuentes del derecho de la Unión Aduanera".

Dada definición debe fundarse como mínimo en dos significados: formal-jurídico, examinado desde el punto de vista del derecho positivo y es material-jurídico. La afirmación expresada permite incluir (en el sentido ancho) en las fuentes del derecho aduanero las decisiones APEC declarativas; ya que, la fuente del derecho no son solamente las fuentes de las normas, pero es la fuente del resultado jurídico1o.

\section{CONCLUSIONES}

Así, caracterizando los niveles supranacionales y nacionales de la regulación en la Unión Aduanera se puede llegar a las siguientes conclusiones:

En el mecanismo de la regulación que se ha formado en la Unión Aduanera son presentados dos subsistemas: uno de ellos funciona en todo el territorio único de la Unión Aduanera y coincide con la noción de la legislación de la Unión Aduanera; otra, se aplica en el nivel nacional, cuando las relaciones correspondientes aduaneras no son ajustadas por la legislación de la «Unión», y son llevados a la esfera de la legislación de uno de los estados miembros de la Unión Aduanera.

En el sistema de la legislación de la Unión Aduanera se separan los niveles supranacionales y nacionales de la regulación. La dirección estratégica de las relaciones en los límites de la Unión Aduanera se realiza contractualmente por los tratados internacionales.

La inclusión de las actas de la regulación supranacional en el mecanismo del sistema nacional jurídico de la Federación Rusa y otros participantes de la Unión Aduanera, es un nuevo fenómeno, único en el derecho ruso. Determinando el lugar de las actas del órgano supranacional en el sistema de las fuentes de la legislación de la Unión Aduanera. El Código Aduanero establece que tales actas se ponen en concordancia con el Código Aduanero y los tratados internacionales de los estados miembros de la Unión Aduanera. Así, se establece «el decreto», el carácter de las actas del órgano supranacional, que se ponen en el desarrollo y en la realización «del derecho primario» de la Unión Aduanera. El Código y los tratados

\footnotetext{
${ }^{8}$ GRANAT, Nina, Las fuentes del derecho, Rusia, Jurista, 1998, № 9, p. 6.

9 ORDINA, Olga, Las fuentes del derecho administrativo de Rusia y el problema de su sistematización: monografía, Rusia, 2010, p. 20.

${ }^{10}$ IVANOV, Vitaliy, Las preguntas generales de la teoría del tratado, Rusia, 2000, p. 15.
} 
internacionales de los estados miembros de la Unión que componen en conjunto la base tratado-jurídica de la Unión Aduanera.

El hecho de la inclusión de las actas del órgano supranacional en la base del tratadojurídica de la Unión Aduanera se confirma en el Tratado sobre la Comisión Eurasiática Económico: «las decisiones de la Comisión entran en la base tratado-jurídico de la Unión Aduanera y el Espacio Económico Común están sujetos a la aplicación directa en los territorios de las Partes». Además, las decisiones del órgano supranacional no son los tratados internacionales en la comprensión de la Ley federal del 15 de julio de 1995, № 101-LF «Sobre los tratados internacionales de la Federación Rusa».

Debemos distinguir los tratados internacionales que forman parte de la legislación y las bases contractuales que componen la Unión Aduanera y los tratados internacionales, ratificado por lo menos por uno de los estados miembros, además que no se refieren a la base contractual de la Unión Aduanera. Sin ser las actas de la legislación, intervienen como las fuentes del derecho nacional aduanero, funcionan en el territorio del estado y tienen la fuerza preponderante en caso de la colisión del los tratados internacionales y del acta nacional legislativa sobre las aduanas.

Los procesos de integración que pasan en la comunidad mundial han traído los cambios esenciales a todos los que han tocado los sistemas jurídicos, incluso la Unión Aduanera. En relación a esto, en la etapa moderna debe más detalladamente revelar el círculo de las fuentes del derecho aduanero en la Unión Aduanera. Entre las numerosas preguntas que tocan el derecho la Unión Aduanera, es importante la pregunta de sus fuentes porque según cómo es solucionado el problema indicado, es decir, que fenómenos jurídicamente significativos confiesan la cualidad de las fuentes, depende del contenido y del carácter de la rama dada. Para el derecho de la Unión Aduanera es característico el sistema, único y relativamente independiente de las fuentes del derecho, en que debe también incluir las normas «soft law», (por ejemplo, aceptado en forma de las actas APEC).

XII. FUENTES

GRANAT, Nina, Las fuentes del derecho, Rusia, Jurista, 1998, № 9, p. 6.

IOFFE, Olimpiad, HARGORODSKIY, Miguel, Las preguntas de la teoría del derecho, Rusia, 1961, p. 134.

IVANOV, Vitaliy, Las preguntas generales de la teoría del tratado, Rusia, 2000, p. 15.

ORDINA, Olga, Las fuentes del derecho administrativo de Rusia y el problema de su sistematización: monografía, Rusia, 2010, p. 20.

Vladivostok-2012: El aviso ruso para el foro APEC. (El Artículo del Presidente de Rusia Vladímir Putin, instalado en la edición asiática del periódico principal americano de trabajo «The Wall Street Journal»), //http://rus.apec2012.ru, 22 de abril de 2014.

DISPOSICIONES NORMATIVAS:

Código Aduanero de la República Bielorrusia. 
Código Aduanero de la Unión Aduanera.

Código de la República Kazajistán.

Convención Internacional de la simplificación y la armonización de los procedimientos aduaneros.

Decisión "Sobre la aplicación del método de la adición a la definición del coste aduanero de las mercancías".

Decisión "Sobre la afirmación de la nomenclatura única mercantil del comercio exterior y la tarifa única de la Unión Aduanera".

Decisión "Sobre la aplicación por la República Bielorrusia y la República Kazajistán de los tipos impositivos, diferentes de tipos de la tarifa única de la Unión Aduanera respecto a las categorías separadas de las mercancía".

Decisión "Sobre algunas cuestiones de la aplicación de las medidas especiales protectoras, antidumping y de compensación en el territorio único aduanero del la Unión Aduanera".

Declaración de Arusha sobre la ética profesional.

Ley federal «Sobre los tratados internacionales de la Federación Rusa».

Ley federal del "Sobre la regulación aduanera en la Federación Rusa".

Tratado constitutivo de la Comunidad Económica Eurasiática.

Tratado sobre la Comisión Eurasiática económica. 